Article

\title{
Impact of mechanical vibrations introduced by up blasting on the structure and hardness of welds on P235GH steel during MAG welding process
}

\author{
Arkadiusz Krajewski 1,* , Paweł Kołodziejczak ${ }^{1}$, Xiaoming Wang² \\ ${ }^{1}$ Warsaw University of Technology, Poland \\ Paweł Kołodziejczak Ph.D.; pkolodzi@wip.pw.edu.pl; \\ 2 National Key Laboratory for Remanufacturing, Beijing, China \\ Xiaomi Wang Ph.D. \\ * Correspondence: Akradiusz Krajewski Ph.D., D.Sc.; akrajews@wip.pw.edu.pl \\ Received: 01.09.2019; Accepted: 10.12.2019
}

\begin{abstract}
This article discusses the effects of surfacing with the introduction of mechanical vibrations into the material using shot blasting. It does not require a rigid attachment of the vibrating system to the base material, and vibrations are introduced as a result of supplying energy of collision of the shot with the parent material. The effect of introducing mechanical vibrations through shot blasting during welding of P235GH steel on the structure and hardness of obtained structures was described. Comparative results of tests revealing the basic differences in the structural structure and hardness of reached welds without shot blasting and with its participation were presented. As a result of the conducted research, differences in the structural structure of the welds were shown and it was shown that shot blasting is an effective and alternative method of introducing mechanical vibrations supporting welding processes.
\end{abstract}

Key words: mechanical vibrations; up blasting; MAG surfacing

\section{Introduction}

Available literature items in the field of the impact of mechanical vibrations during welding processes inform that their proper application leads to an improvement in the structure of welded joints understood as a reduction in the size of grains, an improvement in their shape similar to equiaxed grains, and a change in

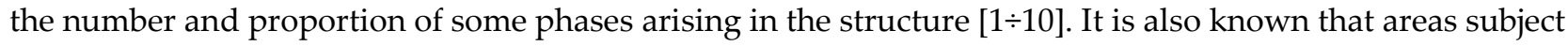
to melting change, those that lie close to the fusion line, as well as the heat affected zone itself [7]. Generally, it can be said that welding processes carried out with a controlled proportion of mechanical vibrations allow to improve the structure of obtained welded joints or padding welds. It should also be noted that the aforementioned changes in the structure are much more pronounced in the case of processes related to welding, namely in casting. This is perhaps because the crystallization process takes much longer in this case than with welding processes and we gain here by reducing the dynamics of crystallization. However, in

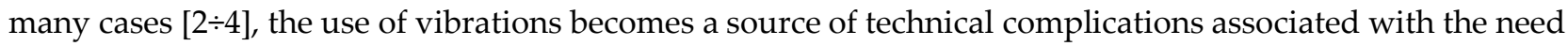
to use complex vibrating systems, vibration generators, etc. The closeness of the source of the vibration and the liquid metal pool is also a considerable problem, which causes the risk of damaging the vibrating system. The vast majority of methods of introducing mechanical vibrations known from the literature require ensuring perfect contact of the elements of the vibrating system with the basic material $[1 \div 10]$. One can find studies in which the authors mention that mechanical vibrations were delivered to the welding zone but do not inform about the method of mutual attachment of the basic material and the vibrating system $[1,4,8,9]$. Considering that mechanical vibrations are able to improve the structure of welded joints or padding welds so much that they are an alternative to heat treatment, it is worth considering the use of vibrations while eliminating the technical problems of their application and the risk of damage to the vibrating system. Such works that describe the use of vibrations introduced without the use of vibrating systems inform that it is possible to effectively introduce vibrations into the basic material and their specificity removes some problems such as the risk of proximity to a heat source, the need for some contact

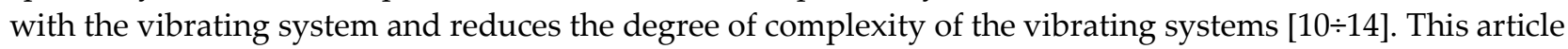
discusses a proposal for such a solution that meets the above assumptions. Vibrations were introduced using the impact variety method [11,12]. It does not require rigid attachment of the vibrating system to the base 
material, and vibrations are introduced as a result of supplying the energy of collision with the shot's substrate (metallic particles with a shape similar to the sphere). The effect of these collisions will depend on many factors. These include the basic ones: the average mass of a particle, its average momentum (kinetic energy), the number of collisions per unit of time, their distribution on the surface of the basic material, and the average size and distance between the shot blasted area and the heat source's welding impact. The article discusses the impact of the new method of introducing mechanical vibrations by shot blasting during surfacing of P235GH steel. Comparative results of metallographic tests revealing the basic differences in the structure of obtained padding welds without shot blasting and with its participation were presented. The results of measuring the hardness of the basic areas of obtained padding welds are also included.

\section{Materials and methodology}

The surfacing experiment was carried out using the MAG method on the surface of a steel pipe with a diameter of $89 \mathrm{~mm}$, wall thickness $3.2 \mathrm{~mm}$ and a length of $2000 \mathrm{~mm}$ (the composition and properties of this steel are included in Table I). The surfacing tests were carried out in a flat position parallel to the pipe axis. The weld No. 1 without mechanical vibrations and the padding weld No. 2 with mechanical vibrations generated in the blasting process were obtained (Figs. 1 and 2). In both cases, M21 shielding gas and Oerlikon Carbofil 1 Gold wire according to EN 440: G 423 C G3 Si1 with a diameter of $1 \mathrm{~mm}$ were used, the composition and properties of which are given in Table II. The padding welds were obtained at the following parameters: $I=100 \mathrm{~A}, U=20 \mathrm{~V}$, wire feed rate $3 \mathrm{~m} / \mathrm{min}$, welding speed $1.5 \mathrm{~m} / \mathrm{min}$ realized by feed of a shot blasting machine.

$\underline{\text { Table I. Chemical composition and properties of P235GH steel acc. to certificate } 3.1 \text { (PN-EN 10204) }}$

\begin{tabular}{|c|c|c|c|c|c|c|c|c|c|}
\hline \multicolumn{10}{|c|}{ Chemical composition [wt.\%] } \\
\hline $\mathrm{C}[\%]$ & $\mathrm{Mn}[\%]$ & $\mathrm{Si}[\%]$ & $\mathrm{P}[\%]$ & $\mathrm{S}[\%]$ & $\mathrm{Cu}[\%]$ & $\mathrm{Cr}[\%]$ & $\mathrm{Ni}[\%]$ & $\mathrm{Al}[\%]$ & $\mathrm{Al}_{\mathrm{sol}}[\%]$ \\
\hline 0.11 & 0.42 & 0.016 & $\leq 0.008$ & $\leq 0.006$ & 0.02 & 0.02 & 0.01 & 0.03 & 0.025 \\
\hline $\mathrm{V}[\%]$ & Mo [\%] & $\mathrm{Nb}[\%]$ & Co $[\%]$ & $\mathrm{Ti}[\%]$ & As [\%] & $\mathrm{N}_{2}[\%]$ & $\mathrm{Ca}[\%]$ & $\mathrm{Pb}[\%]$ & Sn $[\%]$ \\
\hline 0.001 & 0.002 & - & 0.002 & 0.001 & 0.001 & 0.007 & 0.0026 & 0.001 & 0.001 \\
\hline $\mathrm{O}[\%]$ & $\mathrm{H}_{2}[\%]$ & $\mathrm{Zn}[\%]$ & $\mathrm{W}[\%]$ & $\mathrm{B}[\%]$ & $\mathrm{Zr}[\%]$ & CEv [\%] & & & \\
\hline- & - & 0.0012 & 0.001 & 0.0002 & 0.0006 & 0.19 & & & \\
\hline \multicolumn{10}{|c|}{ Mechanical properties } \\
\hline \multicolumn{3}{|c|}{$\operatorname{Re}[\mathrm{MPa}]$} & \multicolumn{4}{|c|}{$R_{m}[\mathrm{MPa}]$} & \multicolumn{3}{|c|}{ A5 [\%] } \\
\hline \multicolumn{3}{|c|}{311} & \multicolumn{4}{|c|}{408} & \multicolumn{3}{|c|}{45,6} \\
\hline
\end{tabular}

Table II. Chemical composition and properties of filler metal type EN 440: G 423 C G3 Si1(Oerlikon Carbofil 1 Gold)

\begin{tabular}{cccccccc}
\hline \multicolumn{4}{c}{ Chemical composition [wt.\%] } & \multicolumn{3}{c}{ Mechanical properties } \\
\hline $\mathrm{C}[\%]$ & $\mathrm{Mn}[\%]$ & $\mathrm{Si}[\%]$ & $\mathrm{P} \mathrm{[ \% ]}$ & $\mathrm{S}[\%]$ & $\mathrm{Re}[\mathrm{MPa}]$ & $\mathrm{Rm}[\mathrm{MPa}]$ & $\mathrm{U}\left(-30^{\circ} \mathrm{C}\right)[\mathrm{J}]$ \\
0.08 & 1.5 & 0.9 & $\leq 0.025$ & $\leq 0.025$ & 420 & $500 \div 640$ & $\geq 47$ \\
\hline
\end{tabular}

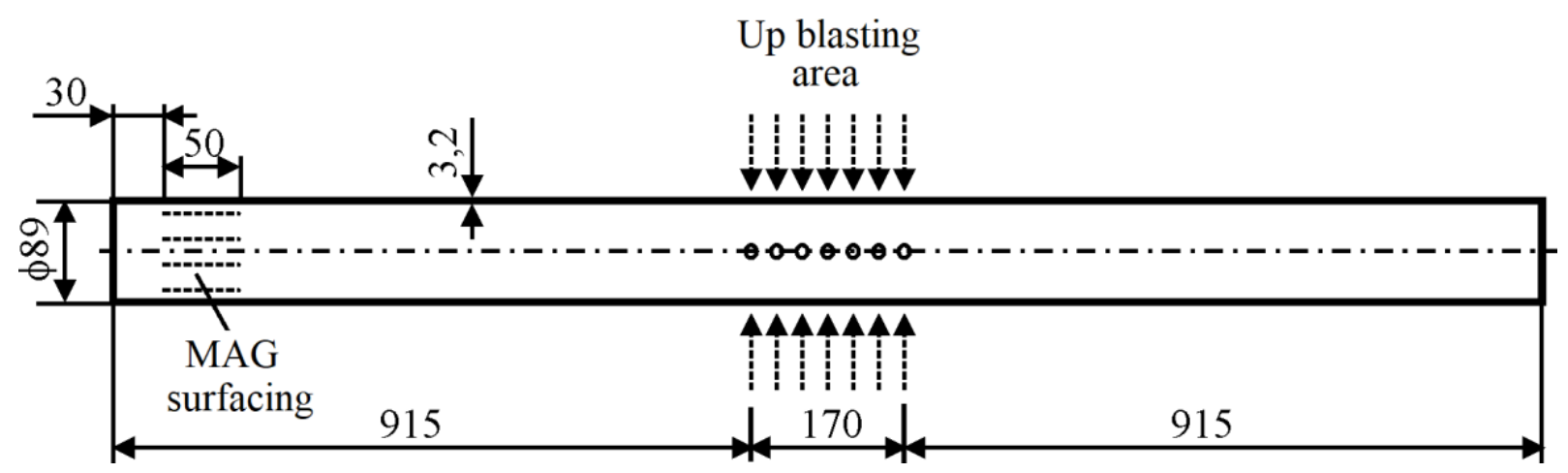

Fig. 1. Diagram of the surfacing process with up blasting 


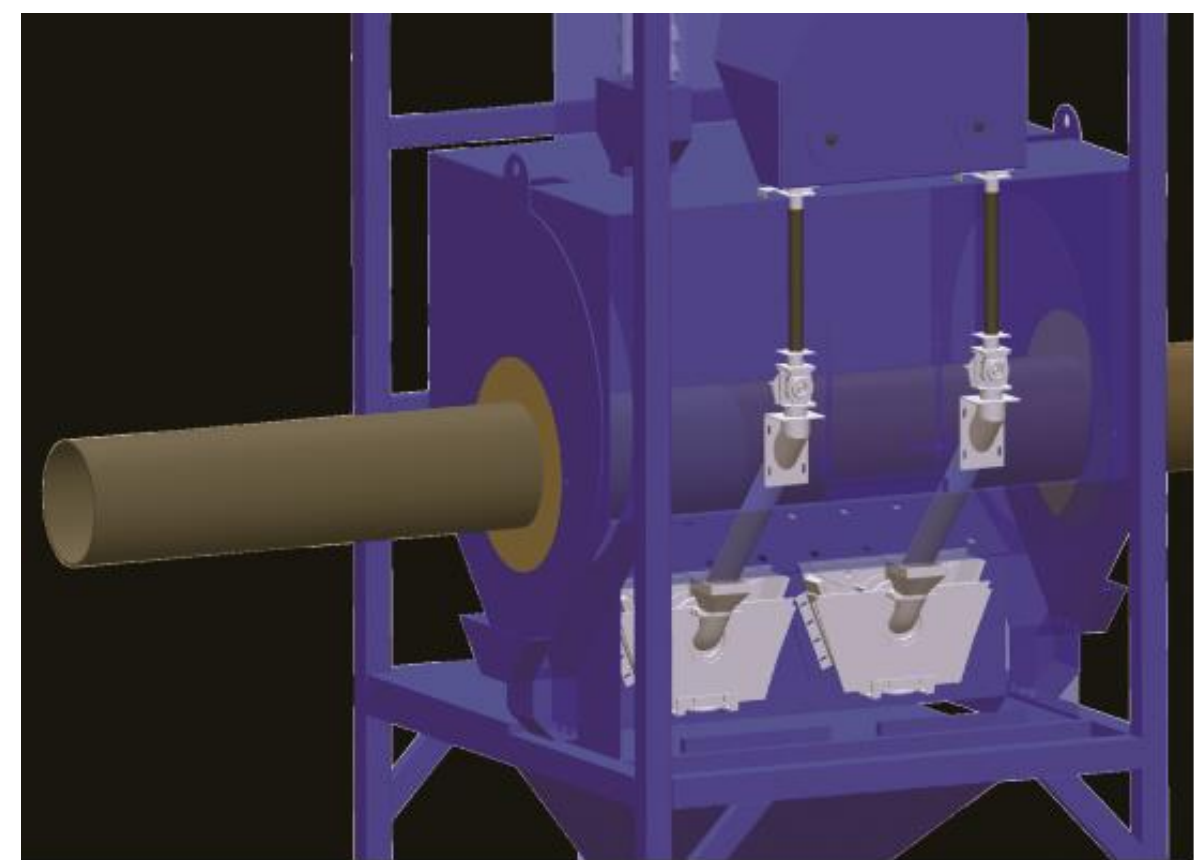

Fig. 2. Figure depicting a real system with a welded and up blasted pipe in the Tilghman Weelabrator device

Shot blasting was carried out in a four-nozzle rotor device (Fig. 2) using steel shot with a diameter of approx. $1.5 \div 2 \mathrm{~mm}$ (Fig. 3).

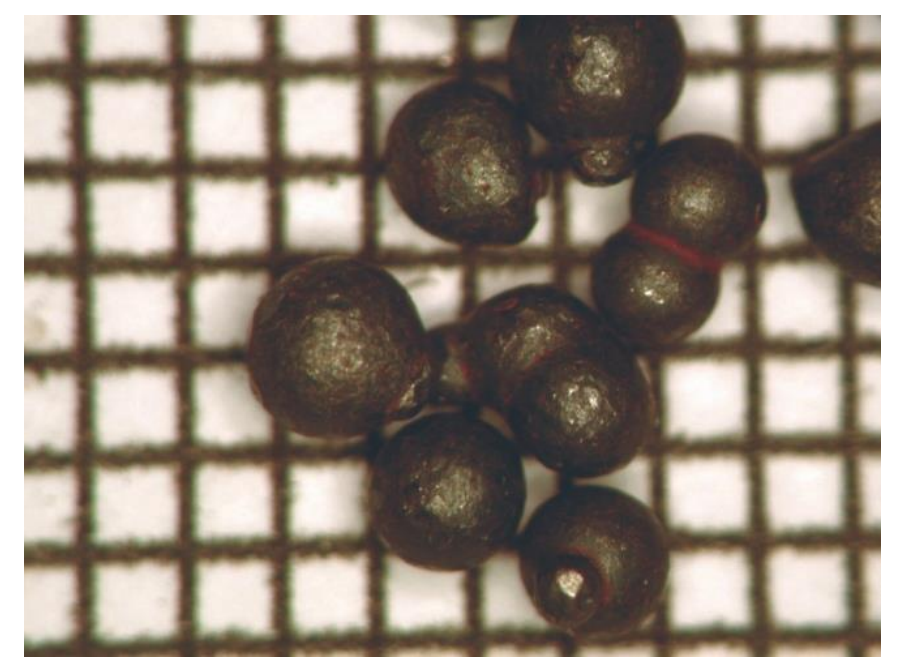

Fig. 3. Steel shot used to introduce vibrations during welding (one grid with $1 \times 1 \mathrm{~mm}$ side)

\section{Research results}

Comparative metallographic tests of the obtained padding welds, quantitative grain size analysis and visual analysis of the darker content in the images of the occurring phase interpreted as perlite were performed after surfacing trials. Hardness measurements were also made using the Vickers method at $100 \mathrm{G}$ load.

\section{Metallographic tests results}

Metallographic tests were carried out on an OLYMPUS BX51M microscope with Stream Essential v. 2.3 software. 16x and 500x magnification was used to show differences in the macrostructural structure as well as the microstructure of individual weld areas such as ridge, face, fusion line or heat affected zone (Fig. 4). The macrostructure photos obtained for the welds allowed to assess the mixing coefficient, face width, height of the weld, which allowed to calculate the shape factor. All parameters are given in table III.

In relation to the obtained welds 1 (without vibrations) and 2 (with vibrations), an average grain size analysis according to ASTM E112-13 was carried out in particular areas such as ridge, face, fusion line and HAZ. The results of this analysis are shown in figure 5. 


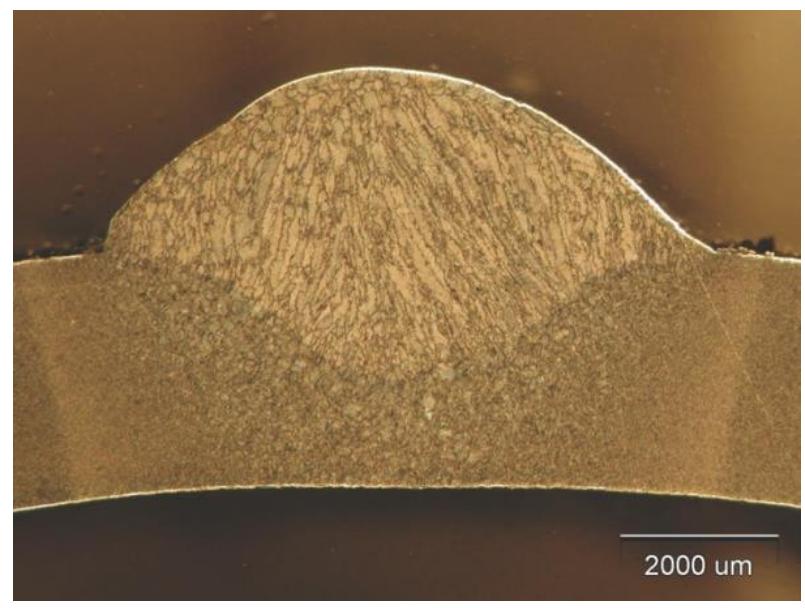

(a)

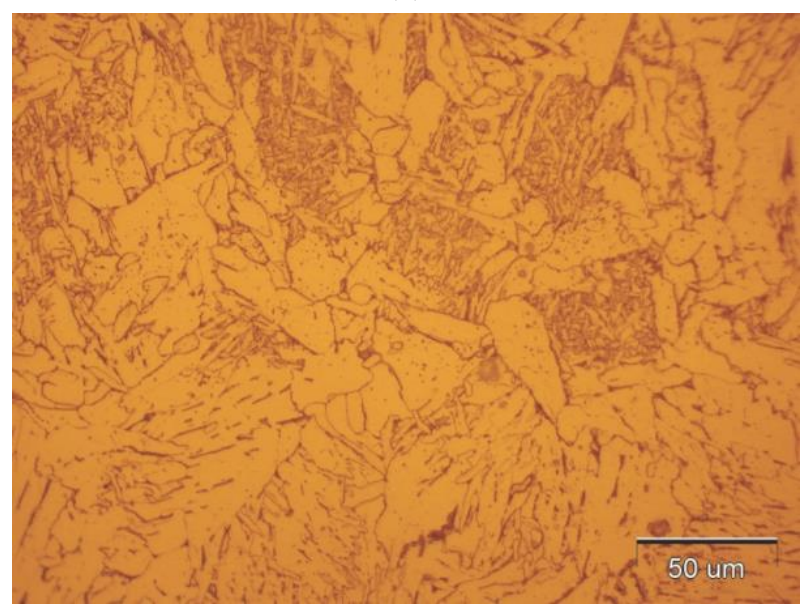

(c)

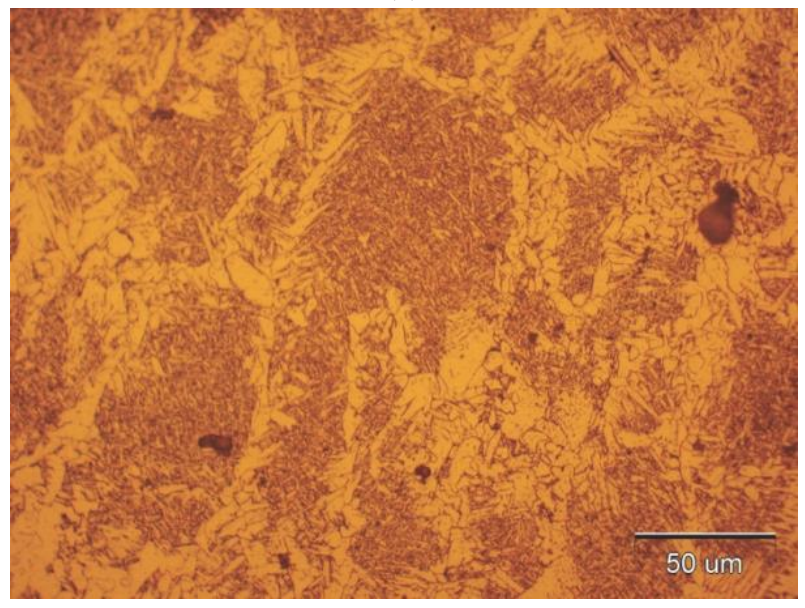

(e)

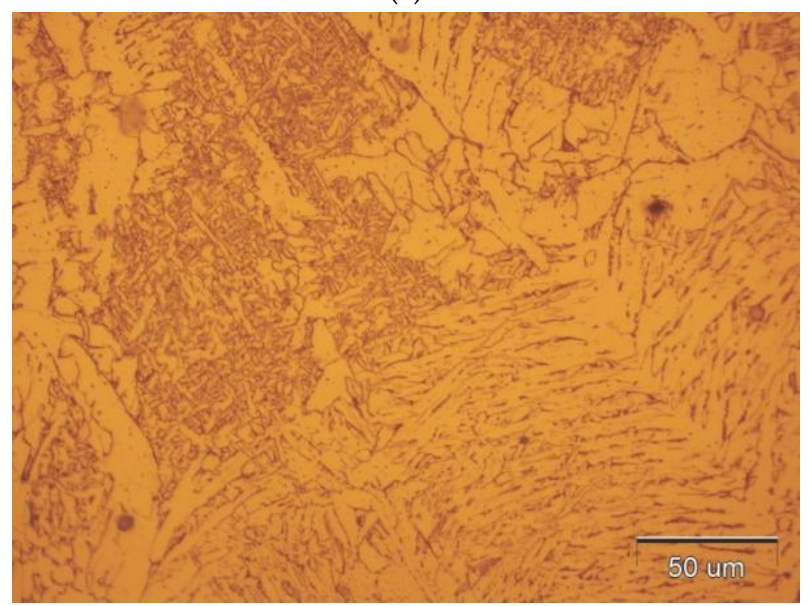

(g)

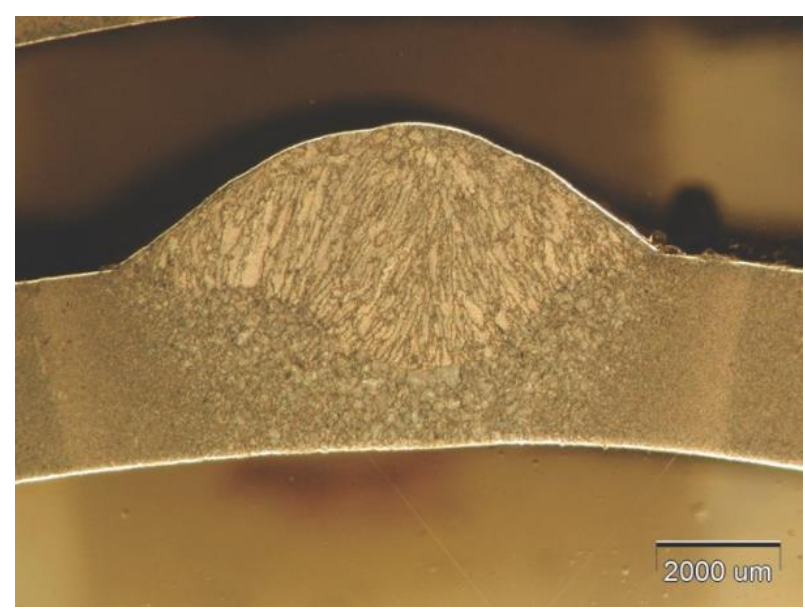

(b)

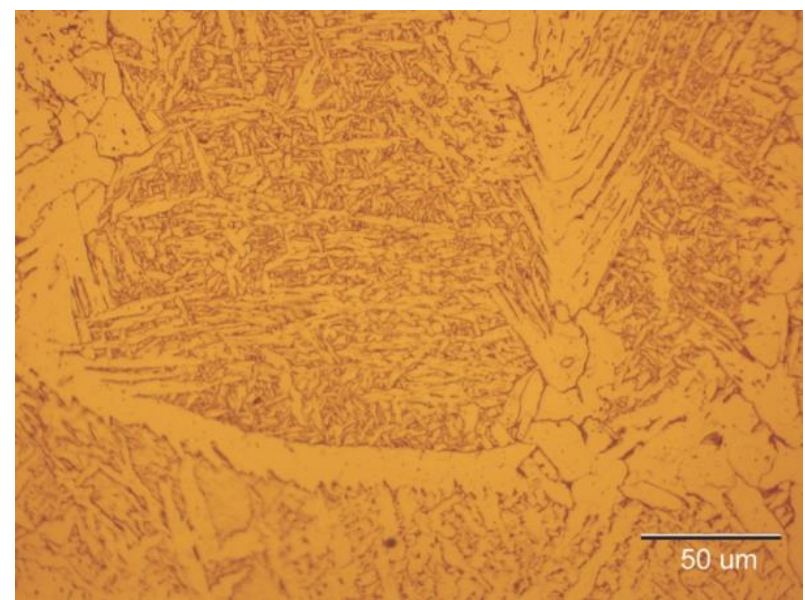

(d)

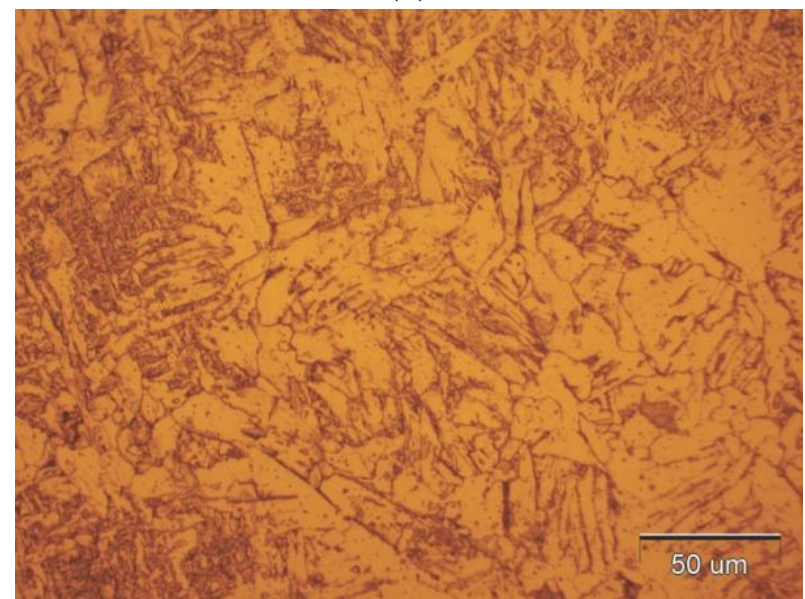

(f)

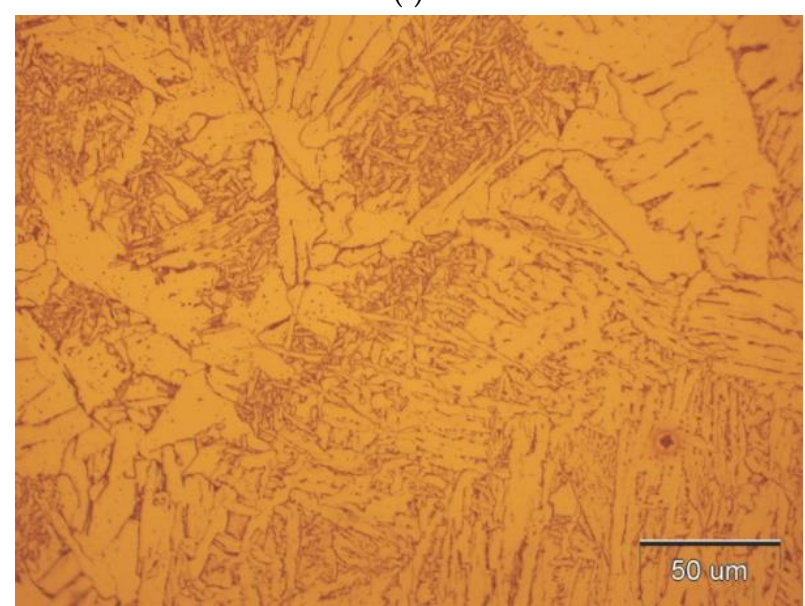

(h) 


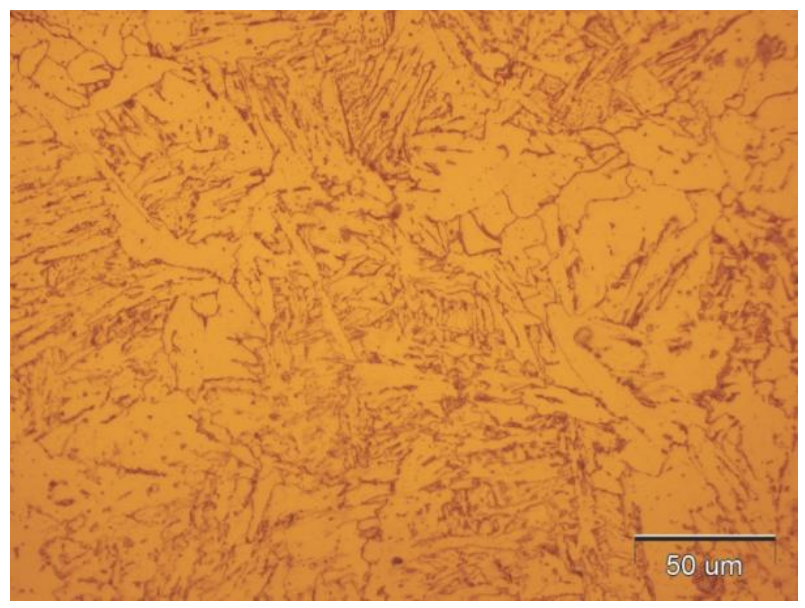

(i)

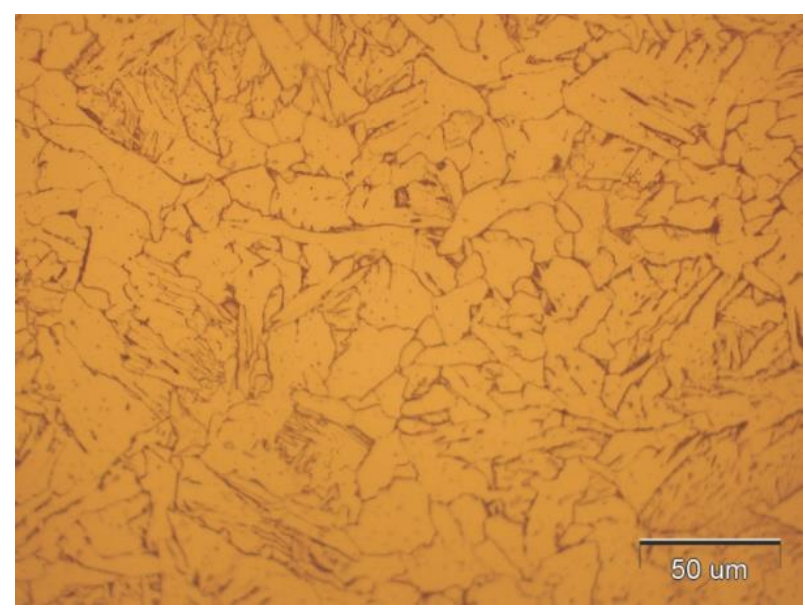

(j)

Fig. 4. Structure of welds; No. 1 reached without up blasting, b) No. 2 reached with up blasting, c) No.1 in the root region ( $16 \%$ perlite), d) No. 2 in the root region ( $26 \%$ perlite), e) No. 1 in the face region ( $32 \%$ perlite), f) No. 2 in the face region ( $25 \%$ perlite), g) No. 1 in the right fusion line (17\% perlite), h) No. 2 in the right fusion line (15\% perlite), i) No. 1 in the HAZ region, j) No. 2 in the HAZ region (11\% perlite)

\section{Assessment of parameters characterizing the geometry}

Based on representative photos of the macrostructure (Fig. 4a and b), the geometrical parameters of the welds were determined, and the degree of mixing and shape of the welds were calculated, and are given in table III. The values of these parameters are average values from measurements for three cross-sections respectively obtained for the case without vibrations and with vibrations.

Table III. Parameters characterizing the weld's shape

\begin{tabular}{ccc}
\hline Parameter & Weld No. 1 & Weld No. 2 \\
\hline Width of the face B [mm] & 7.56 & 8.86 \\
Height of the weld H [mm] & 4 & 4 \\
Shape factor B/H & 1.89 & 2.22 \\
Degree of mixing W [\%] & $38 \%$ & $44 \%$ \\
\hline
\end{tabular}

Average grain size in the root area of weld No. 1

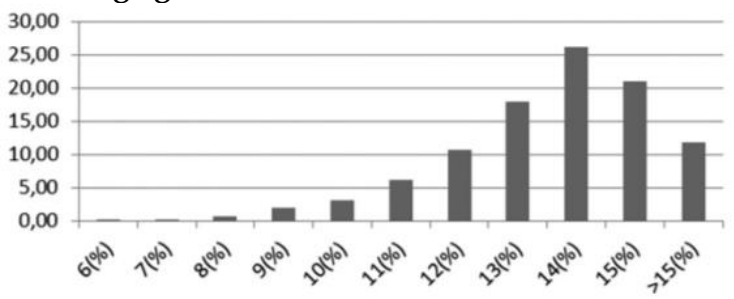

Average grain size in the face area of weld No. 1

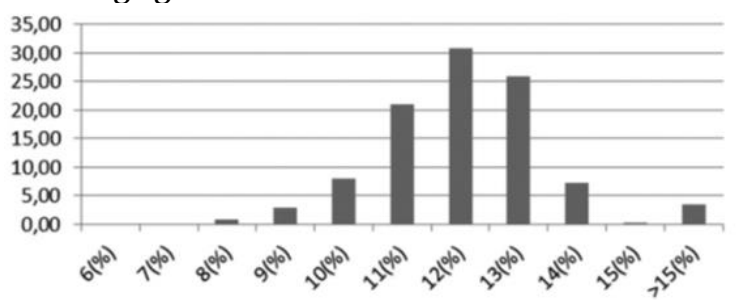

Average grain size in the right fusion line area of weld No. 1

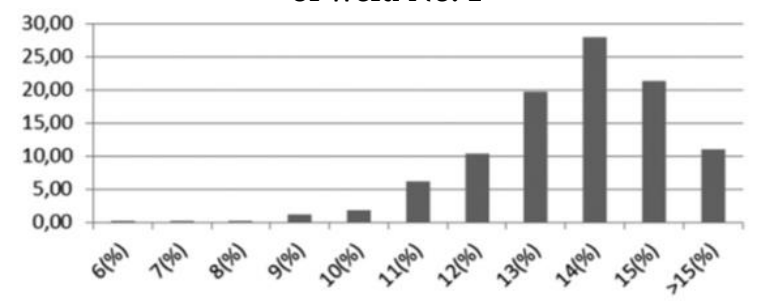

Average grain size in the root area of weld No. 2

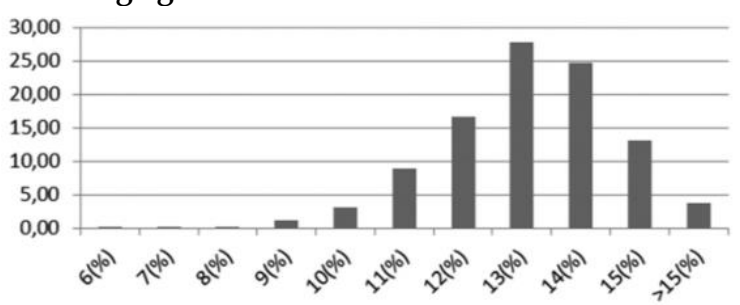

Average grain size in the face area of weld No. 2

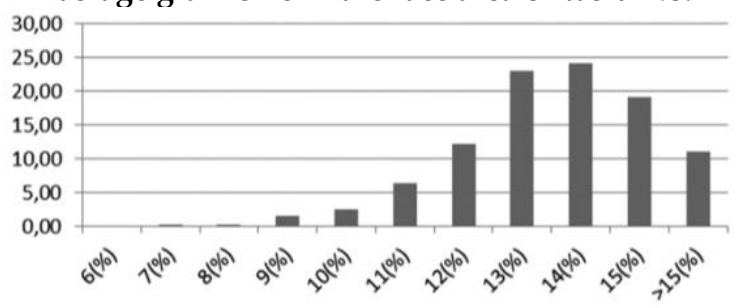

Average grain size in the right fusion line area of weld No.2

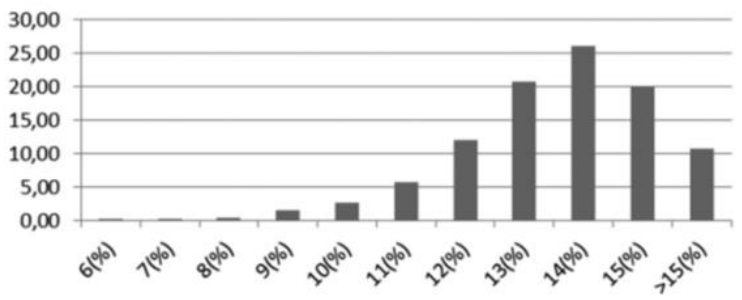


Average grain size in the HAZ area of the weld No. 1

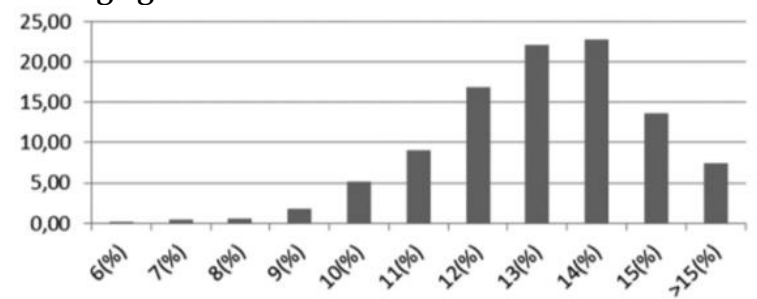

Average grain size in the HAZ area of the weld No. 2

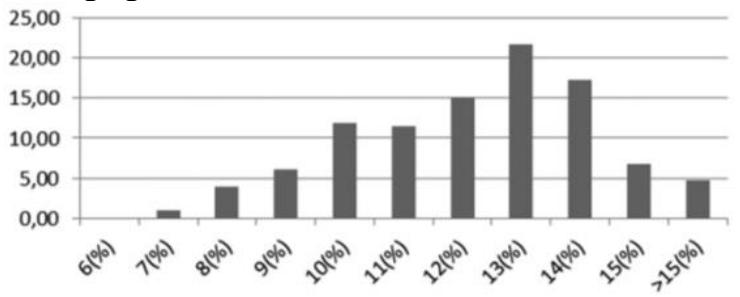

Fig. 5. The results of grain size analysis in characteristic areas of surfacing welds No. 1 and 2 acc. to ASTM E 112-13

\section{Hardness measurement results}

Hardness was measured from the face (where the origin of the coordinate system occurs) towards the ridge. The results of microhardness measurements are shown in figure 6 . On the graph, the points represent the average values of three measurements.

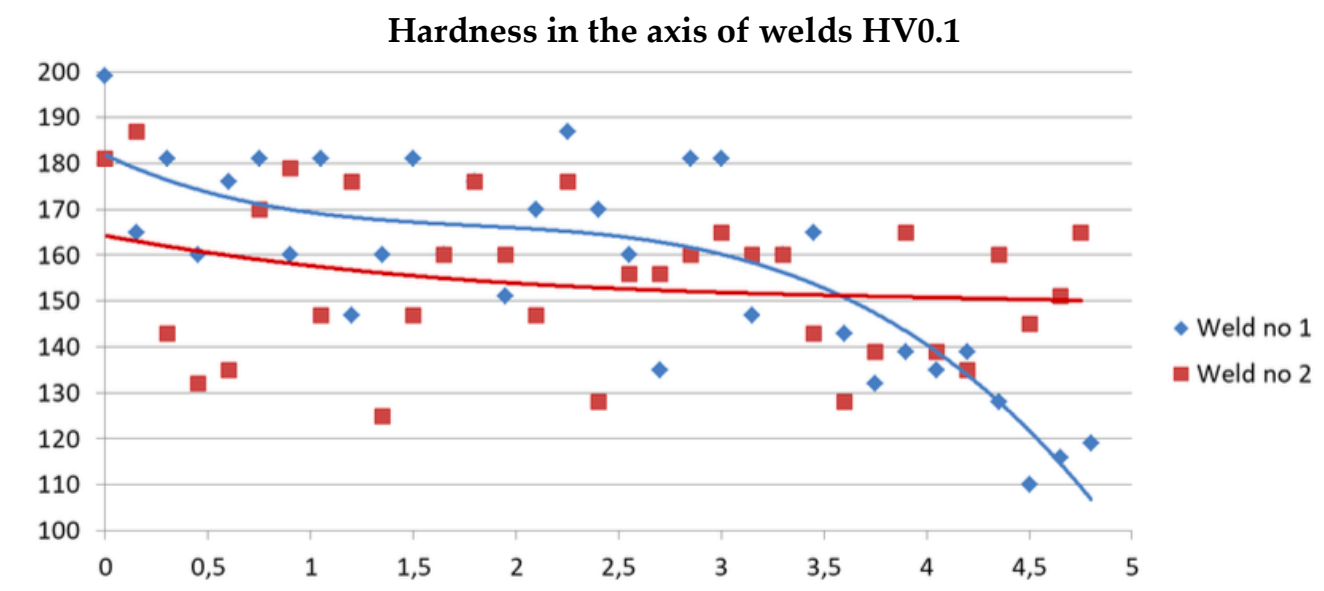

Fig. 6. Results of HV 0.1 hardness measurements in the weld axis (trend lines marked)

\section{Research results discussion}

The observation of the macrostructure of the obtained welds showed that the use of vibrations with the help of a four-nozzle shot blasting machine during the surfacing caused a change in the shape of the padding weld. A wider face was created while maintaining the same height of the weld and the degree of mixing in the padding weld increased.

Photographs of the microstructure taken in the characteristic areas of the welds show significant differences in their structure in relation to the padding weld obtained without vibration and for that with vibration. It can be stated that the greatest diversity of structure occurs in the ridge, face and heat affected zones. This is also confirmed by the analysis of grain size and distribution in these zones. Near the ridge, the introduction of vibrations caused the number of grains with the largest to decrease, and their maximum concentration shifted towards a smaller percentage. In the case of a face, the disappearance of perlite islets can be observed, which is confirmed by a decrease in the maximum grain size and relaxation of the maximum concentration and shifting it towards larger percentages. The heat affected zone also suffered a change in the dendrite breakdown, which resulted in more visible grain equilibrium and a reduction in the maximum grain size and flattening of the grain size distribution.

Microhardness measurements showed that there is a significant difference in its distribution. The hardness distribution in weld No. 1 obtained without the use of shot blasting clearly shows significant variation. Near the face there were higher values than in the middle of the weld and much higher in terms of hardness in the root area. It is also worth noting that the hardness distribution in weld No. 2 obtained with up blasting shows a significant degree of flattening, and the average hardness value is lower by approx. 15 to 20 HV0.1. It is different in the case of ridges. The trend lines of the hardness distribution of both padding welds intersect in the ridge area, and the hardness in the weld No. 1 falls by about 50 HV0.1 compared to padding weld No. 2 . 
Both metallographic tests and microhardness measurements clearly indicate that the blasting process caused visible structural changes as well as the properties of the obtained welds. These changes can be seen as positive, both in terms of grain shape and size, and in terms of homogeneous structure.

\section{Conclusions}

As a result of the described tests, the thesis can be formulated that the use of shot blasting to introduce mechanical vibrations during welding can be an effective process and is an interesting alternative to other more complicated and troublesome methods requiring constant and reliable contact of the vibrating system with the basic material. The fact that this method is common and generally available can be a key aspect of its successful use in future welding. Documented changes in the microstructure and properties of the welds obtained on ordinary low-carbon steel may not solve any significant material nature problem but prove that the shot blasting process should be considered as a replacement method of welding vibration support. Nevertheless, in order for the proposed method to give more predictable and reproducible results, it is still necessary to solve many problems related to the selection and optimization of parameters, such as average mass of shot grain, its average momentum value, collision intensity per unit of time, range and shape of the blasted basic material and the average size and its distance from the place of influence of the welding heat source. The determination of these factors and the description of the vibrations they cause are now a priority in the development of shot blasting technology as a method of introducing mechanical vibrations in welding processes. Shot blasting as a known and common process in the metal industry, when properly used, can ensure the effective introduction of mechanical vibrations and interaction with the liquid metal pool.

Author Contributions: conceptualization A.K.; methodology A.K., P.K., X.W.; investigation A.K., P.K.; discussion A.K., writing - original draft preparation A.K. and editing A.K.

Conflicts of Interest: The authors declare no conflict of interest.

\section{References}

[1] Chen R., Zheng D., Guo J., Ma T., Ding H., Su Y., Fu H., A novel method for grain refinement and microstructure modification in TiAl alloy by ultrasonic vibration, Materials Science E Engineering: A, 2015, vol. 653, $23-26$. [CrossRef]

[2] Krajewski A., Włosiński W., Chmielewski T., Kołodziejczak P., Ultrasonic-vibration assisted arc-welding of aluminum alloys, Bulletin of the Polish Academy of Science, 2012, vol. 60(4), 841-852. DOI: 10.2478/v10175-012-0098-2 [ [Hyperlink]

[3] Watanabe T., Shiroki M., Yanagisawa A., Sasaki T., Improvement of mechanical properties of ferritic stainless steel weld metal by ultrasonic vibration, Journal of Materials Processing Technology, 2010, vol. 210(12), 1646-1651. [CrossRef]

[4] Dong H., Yang L., Dong C., Kou S., Improving arc joining of Al to steel and Al to stainless steel, Materials Science and Engineering: A, 2012, vol. 534, 424-435. [CrossRef]

[5] Krajewski A., Mechanical vibrations in welding processes, Przeglad Spawalnictwa, 2011, vol. 83(6), 37-42. [CrossRef]

[6] Krajewski A., Impact of the ultrasonic vibration phase on the structure and hardness of 2017A aluminum alloy welds, Przeglad Spawalnictwa, 2013, vol. 85(1), 45-50. [CrossRef]

[7] Krajewski A., Influence of mechanical vibrations used in welding processes on the properties of welded joints, vol. 258, ISSN 978-83-7814-118-1, Publishing House of Warsaw University of Technology, 2013.

[8] Chen Q., Lin S., Yang C., Fan C., Ge H., Grain fragmentation in ultrasonic-assisted TIG weld of pure aluminum, Ultrasonics Sonochemistry, 2017, vol. 39, 403-413. [CrossRef]

[9] Singh P. K. ,Patel D., Prasad B. S., Development of Vibratory Welding Technique and Tensile Properties Investigation of Shielded Metal Arc Welded Joints, Indian Journal of Science and Technology, 2016, vol. 9(35), 2016, DOI: 10.17485/ijst/2016/v9i35/92846 [ Hyperlink]

[10] Radel T., Thermal Impact in vibration-assisted laser deep penetration welding of aluminium, Physics Procedia, 2017, vol. 89, 131-138. [CrossRef]

[11] Mordyuk B. N., Prokopenko G. I., Ultrasonic impact peening for the surface properties' management, Journal of Sound and Vibration, 2007, vol. 308(3-5), 855-866. [CrossRef]

[12] Ishikawa T., Nakashima K., Nose T., Method of increasing toughness of heat-affected part of steel product welded joint, European Patent Application, EP1559796A1, 2005. 
[13] Nothdurft S., Springer A., Kaierle S., Ohrdes H., Twiefel J., Wallaschek J., Mildebrath M., Maier H. J., Hassel T., Overmeyer L., Laser welding of dissimilar low-alloyed steel-steel butt joints and the effects of beam position and ultrasound excitation on the microstructure, Journal of Laser Applications, 2018, vol. 30(3), 1-6. [CrossRef]

[14] Zhou S., Ma G., Wu D., Chai D., Lei M., Ultrasonic vibration assisted laser welding of nickel-based alloy and Austenite stainless steel, Journal of Manufacturing Processes, 2018, vol. 31, 759-767. [CrossRef]

(C) 2019 by the authors. Submitted for possible open access publication under the terms and conditions of the Creative Commons Attribution (CC BY) license (http://creativecommons.org/licenses/by/4.0/). 